\title{
Recurrent upper gastrointestinal ulcer bleeding treated by coil embolization guided by endoscopic ultrasonography
}

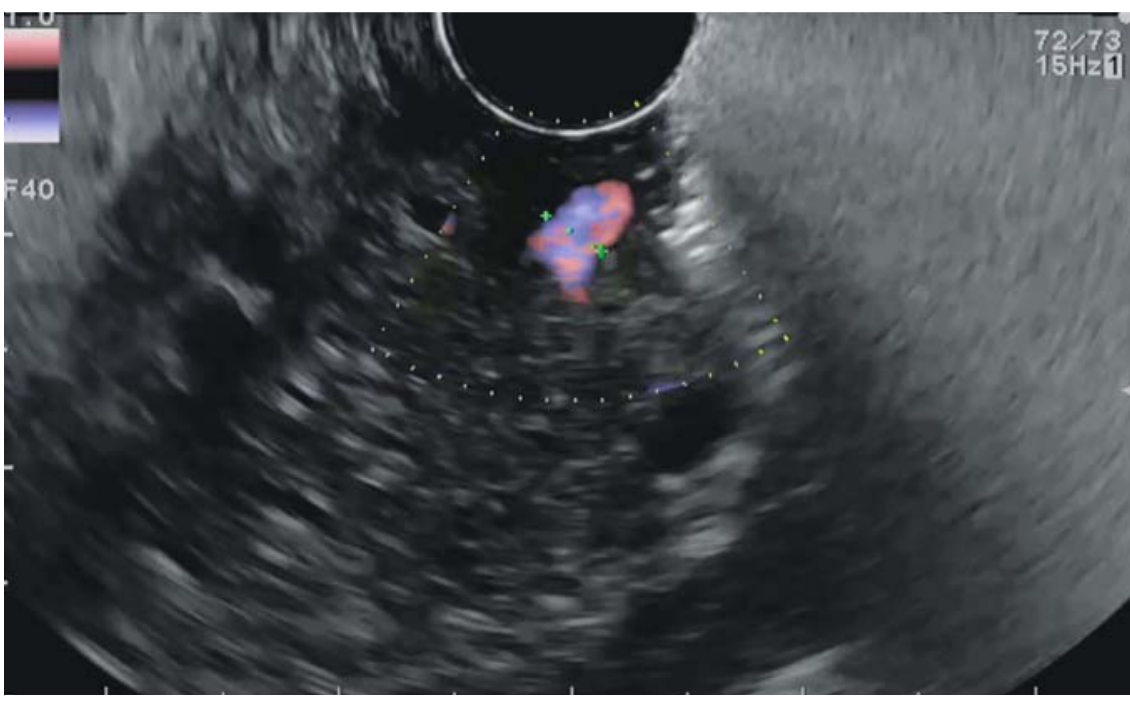

Fig. 1 Endoscopic ultrasonogram showing a 2.8-mm arterial vessel at the base of the ulcer.

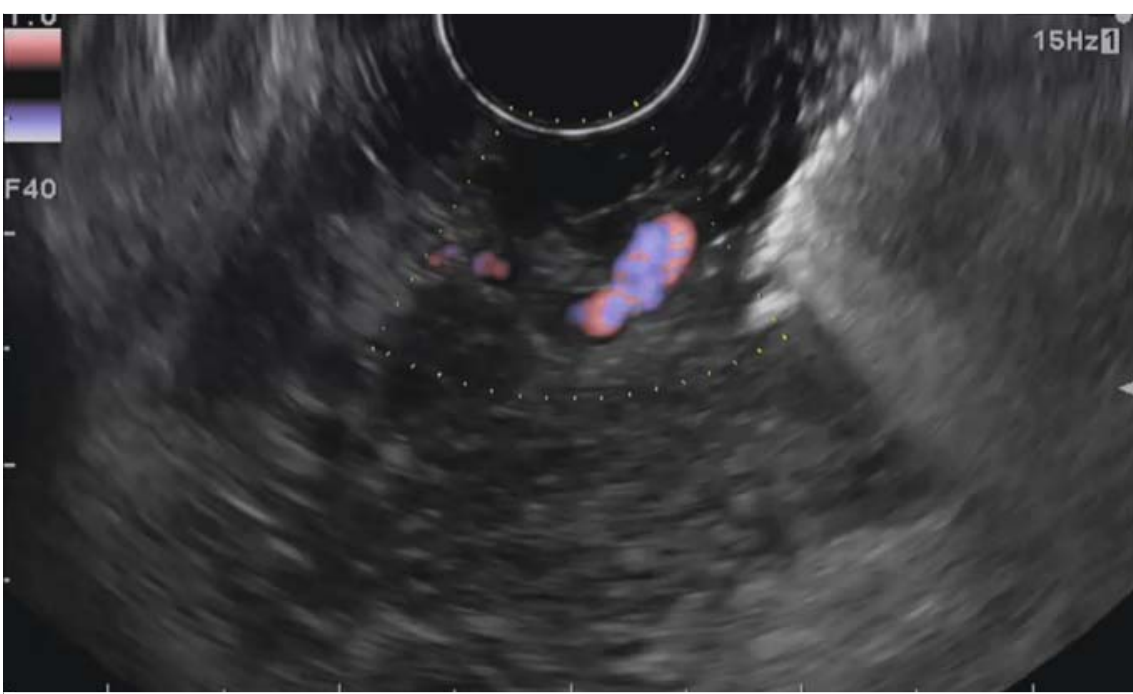

Fig. 3 Endoscopic ultrasonogram revealing at the base of the ulcer a 4-mm arterial vessel originating from the gastroduodenal artery.

Clinical case 1. A 45-year-old man diagnosed with locally advanced pancreatic adenocarcinoma was admitted to hospital for acute upper gastrointestinal bleeding (UGIB). Urgent gastroscopy showed a duodenal ulcer of about $15 \mathrm{~mm}$ and a visible vessel. The first treatment option was to inject diluted adrenaline and place two hemoclips. Despite the treatment, progressive anemia persisted.

Repeat endoscopic assessment showed the visible vessel without the previously placed hemoclips. Endoscopic ultrasonography (EUS) allowed identification at the base of the ulcer of a 2.8-mm arterial vessel originating from the gastroduode-

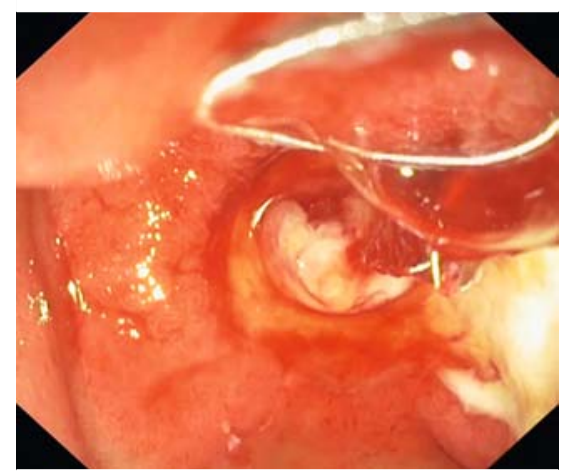

- Fig. 2 Postembolization endoscopic view. The exit of one of the coils through the ulcer can be seen.

nal artery ( $\triangleright$ Fig. 1 ). The vessel was embolized using a 0.018-inch Tornado coil (Cook Inc., Bloomington, Indiana, USA) through a 22-G needle (Boston Scientific Corp., Natick, Massachusetts, USA). A later check showed absence of active bleeding ( $>$ Fig. 2, $>$ Video 1 ).

Clinical case 2. A 77-year-old man diagnosed with nasopharyngeal carcinoma was admitted to hospital for UGIB. Urgent gastroscopy showed a penetrating duodenal ulcer with a large visible vessel. Due to the size of the vessel, the initial treatment option was sclerosis using diluted adrenaline without hemoclips. EUS was performed and identified a 4-mm arterial vessel (> Fig. 3 ) which was treated with injection of $n$-butyl-2-cyanoacrylate (Histoacryl; B. Braun, Melsungen, Germany), with a good result.

Despite the treatment, however, anemia persisted, so an endoscopic reevaluation was requested. Repeat EUS verified persistence of flow in the vessel. The vessel was embolized using a 0.018-inch Tornado coil (Cook Inc.) through a 22-G needle (Boston Scientific Corp.). A later check showed absence of flow ( $\triangleright$ Fig. 4 ).

The most common type of acute UGIB is "nonvariceal." Peptic ulcers account for $28 \%-59 \%$ of the total. The first treatment option is dual therapy with adrena- 


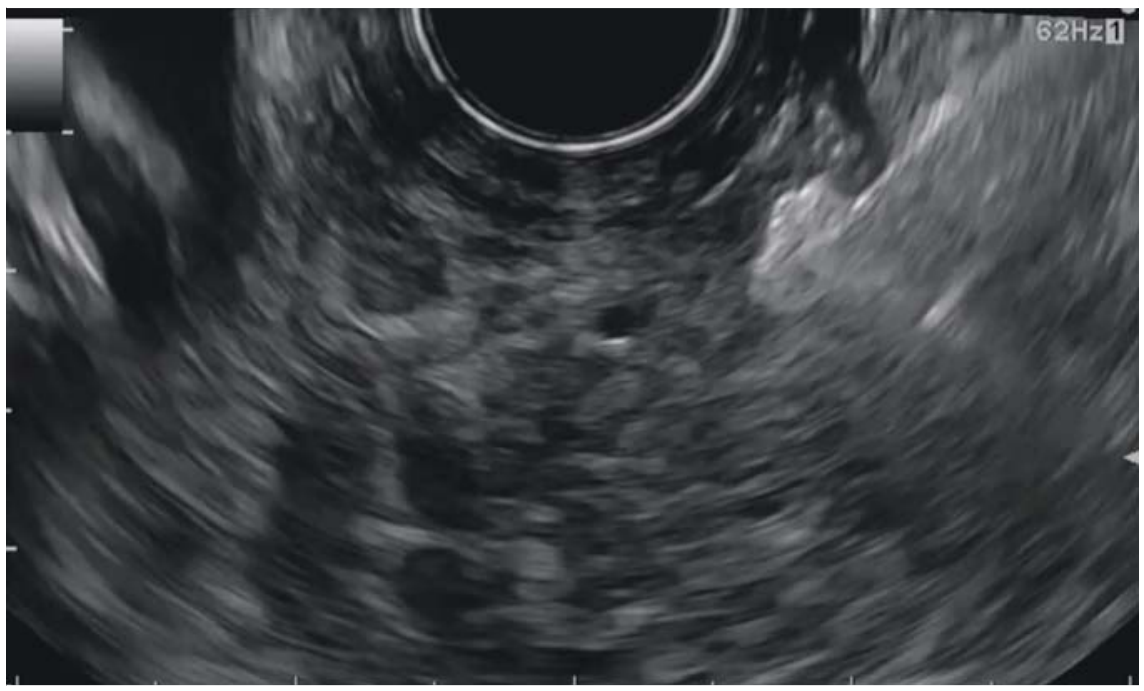

- Fig. 4 Absence of flow after EUS-guided embolization with two 0.018-inch Tornado coils.

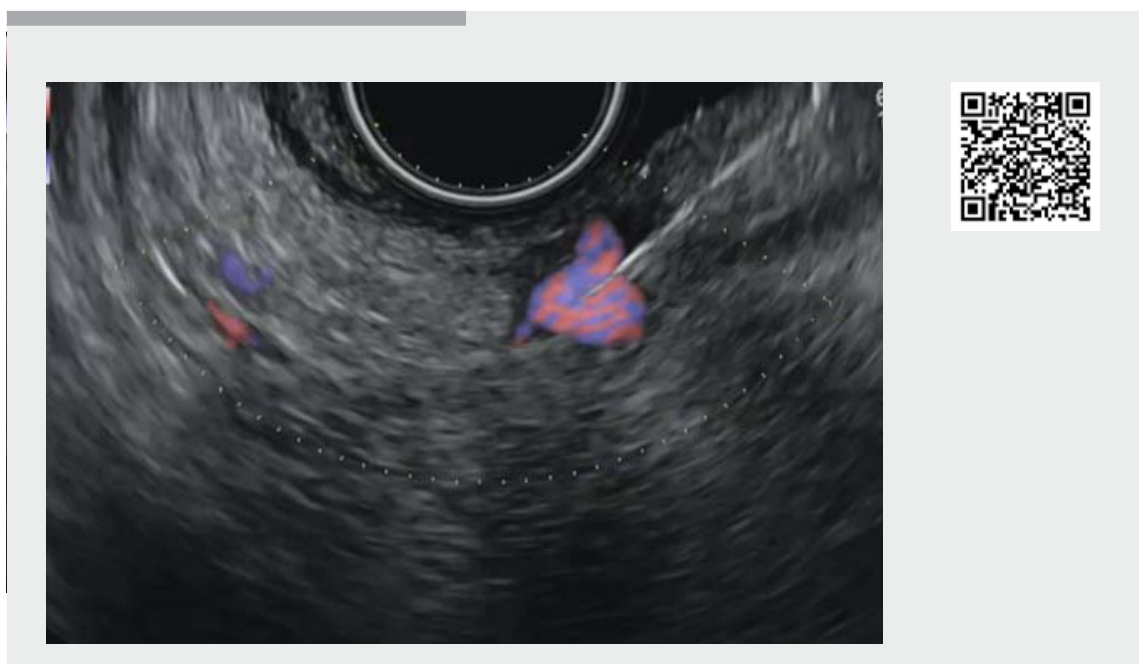

Video 1 EUS-guided embolization with coils in two patients with recurrent ulcer bleeding.

line and mechanical or thermal methods [1]. If this treatment fails, interventional radiology with arterial embolization is the treatment of choice before surgery [2].

Endoscopic coiling has been widely used to embolize fundal or subcardial varices $[3,4]$. However, there has been no previous experience in the treatment of UGIB secondary to peptic ulcers. Although comparative studies are needed, EUS-guided coil embolization can be an
The authors

Lucía Medina-Prado ${ }^{1,2}$, Sandra Baile-Maxía ${ }^{1,2}$, Maryana Bozhychko ${ }^{1,2}$, Carolina MangasSanjuan ${ }^{1,2}$, Juan Martínez-Sempere ${ }^{1,2}$, Juan Antonio Casellas $^{1,2}$, José Ramón Aparicio ${ }^{1,2}$

1 Endoscopy Unit, Department of Gastroenterology, Hospital General Universitario de Alicante, Alicante, Spain

2 Instituto de Investigación Sanitaria y Biomédica de Alicante (Isabial), Alicante, Spain

\section{Corresponding author}

\section{José Ramón Aparicio, MD}

Endoscopy Unit, Hospital General

Universitario de Alicante, C/ Pintor Baeza 12, 03010, Alicante, Spain

japariciot@gmail.com

\section{References}

[1] Cañamares-Orbís P, Chan FKL et al. Endoscopic management of nonvariceal upper gastrointestinal bleeding. Best Pract Res Clin Gastroenterol 2019; 42-43: 101608

[2] Katano T, Mizoshita T, Senoo K et al. The efficacy of transcatheter arterial embolization as the first-choice treatment after failure of endoscopic hemostasis and endoscopic treatment resistance factors. Dig Endosc 2012; 24: 364-369

[3] Bhat YM, Weilert F, Fredrick RT et al. EUSguided treatment of gastric fundal varices with combined injection of coils and cyanoacrylate glue: a large U.S. experience over 6 years (with video). Gastrointest Endosc 2016; 83: 1164-1172

[4] Samuel R, Bilal M, Tayyem O et al. Evaluation and management of non-variceal upper gastrointestinal bleeding. Disease-a-month 2018; 64: 333-343

effective treatment option when standard treatment fails.

Endoscopy_UCTN_Code_TTT_1AO_2AN

\section{Competing interests}

Dr. Aparicio is a consultant for Boston Scientific. The other authors declare that they have no conflict of interest.

\section{Bibliography}

Endoscopy 2020; 52: E424-E425

DOI $10.1055 / a-1158-8488$

ISSN 0013-726X

published online 6.5.2020

(C) 2020. Thieme. All rights reserved.

Georg Thieme Verlag KG, Rüdigerstraße 14,

70469 Stuttgart, Germany 